\title{
USE OF HUMAN IMMUNOGLOBULIN IN DERMATOMYOSITIS WITH SEVERE PULMONARY INVOLVEMENT - CASE REPORT
}

Thiago Reis De Santana (UNIVERSIDADE FEDERAL DE SERGIPE, ARACAJU, SE, Brasil), Telma Rodrigues Santos Da Paixao (UNIVERSIDADE FEDERAL DE SERGIPE , ARACAJU, SE, Brasil), Giovana Dutra Saquy

(UNIVERSIDADE FEDERAL DE SERGIPE , ARACAJU, SE, Brasil), Luiza Todt Cardoso De Faro

(UNIVERSIDADE FEDERAL DE SERGIPE , ARACAJU, SE, Brasil), Regina Adalva De Lucena Couto Ocea (UNIVERSIDADE FEDERAL DE SERGIPE , ARACAJU, SE, Brasil), Lina Oliveira De Carvalho (UNIVERSIDADE FEDERAL DE SERGIPE , ARACAJU, SE, Brasil), Blenda Hilíria De Sousa Dias (UNIVERSIDADE FEDERAL DE SERGIPE , ARACAJU, SE, Brasil), Monica Valeria Siqueira Santana De Vechi (UNIVERSIDADE FEDERAL DE SERGIPE , ARACAJU, SE, Brasil), Jose Caetano Macieira (UNIVERSIDADE FEDERAL DE SERGIPE, ARACAJU, SE, Brasil)

\section{BACKGROUND}

Pulmonary involvement in dermatomyositis is characterized by a broad spectrum of gravity, which can lead to respiratory failure. Treatment is based on the use of pulse therapy with methylprednisolone and immunosuppressants such as cyclophosphamide and mycophenolate mofetil. In refractory cases, rituximab and / or human immunoglobulin may be used.

\section{CASE REPORT}

A 42-year-old female patient, with a fibrotic lesion in the right thigh with a biopsy compatible with panniculitis. It evolved with photosensitivity, erythema on face, shawl signal, heliotrope, Gottron's sign on elbows, Gottron's papules, periungual vasculitis, alopecia, asthenia, polyarthralgia. Subsequently with dysphonia, proximal and symmetrical muscular weakness of upper limbs (grade 3) and lower limbs (grade 2), progressive dyspnea, dry cough and pleuritic pain, respiratory auscultation with fine crepitations in mid-lower thirds of both hemithorax. Despite the previous use of prednisone, he needed hospitalization due to worsening dyspnea, minimal efforts, and need for supplemental oxygen. Laboratory exams revealed FAN reagent 1/160 dense fine dotted cytoplasmic pattern, Anti-Ro reagent (46.0); Rheumatoid Factor, Anti-Jo-1, Native Anti-DNA, Anti-Sm, Anti-La and Anti-RNP all negatives; C3, C4 and CH50 normal. The femoral quadriceps proximal region biopsy was compatible with inflammatory myopathy. High resolution chest computed tomography revealed multiple areas bilateral, predominantly peripheral, consolidations associated with bronchiectasis and thickening of the intra and interlobular septa, more evident in the lower lobes, compatible with pattern of organized pneumonia. It was submitted to pulse therapy with methylprednisolone $1 \mathrm{~g} /$ day for 3 days, followed by prednisone $1 \mathrm{mg} / \mathrm{kg} /$ day and cyclophosphamide $1 \mathrm{~g}$. However, after 1 month, dyspnea persisted at minimal effort, requiring additional oxygen under a $50 \%$ venturi mask and worsening pulmonary involvement on a new chest computed tomography. Thus, the patient had a new pulse with methylprednisolone $1 \mathrm{~g} /$ day for 3 days, followed by human immunoglobulin $2 \mathrm{~g} / \mathrm{kg}$ in 5 days. After 1 month it evolved with significant improvement of the muscular and respiratory picture, without need of supplemental oxygen. It continues with a monthly schedule of cyclophosphamide, associated with immunoglobulin, with stability.

\section{CONCLUSION}

It is a case of dermatomyositis with pulmonary involvement refractory to the treatment instituted, with improvement after human immunoglobulin use. 